\title{
Empirical analysis of the linkages between the manufacturing and other sectors of the Nigerian economy
}

\author{
D. Salami \& I. Kelikume \\ Department of Accounting, Economics and Finance, Lagos Business \\ School, Lagos State, Nigeria
}

\begin{abstract}
This paper estimates the linkage between the manufacturing sector and other sectors of the Nigerian economy with the aid of a more dynamic estimating tool. The paper departs from the static Leontief's input-output framework used by earlier studies and adopts the Granger causality test and the vector auto regression method, to determine the impact of changes in manufacturing output on the output of the other sectors and the effects of changes in output of other sectors on the manufacturing sector. Using quarterly time series data over the periods 1986 to 2010 the result shows a weak linkage between the manufacturing sector and other sectors of the Nigerian economy. The manufacturing sector output showed no causal relationship with real economic activities as measured by the real gross domestic product. It also had no causal relationship with the financial sector output. Only two major sectors building and construction and hotel and restaurant seems to be driving the manufacturing sector with the later exhibiting a bi-directional relationship with the manufacturing sector. Specifically, it takes approximately four to six quarters for most sectors to respond to the impact of shocks emanating from the other sectors the economy. Keywords: manufacturing sector, sectorial linkage, vector autoregression, granger casualty, real gross domestic product.
\end{abstract}

\section{Introduction}

The manufacturing sector makes significant contribution to economic development through its income and employment linkages with other sectors of the economy in both developing and developed countries. Prior to the twenty 
first century, the manufacturing sector was seen as the main engine of economic growth Cornwell, [1]; Fagerberg and Verspagen [2]; and Timmer and de Vries, [3]. Events' calumniating developmental changes in the twenty first century however, has accorded the service and telecommunication sectors an important place in the growth process in many developing and emerging nations, Szirmal [4]. In Nigeria, intensification of industrial activities is essential for driving the current Federal Government strategy for sustainable development and economic growth. However, the current state of the manufacturing sector leaves much to be desired. Recent data reveal that Nigeria is still operating at the extractive/primary stage of development, Central Bank of Nigeria (CBN) statistical bulletin [5]. The sector currently faces a number of constraints ranging from low local content, weak legal and institutional framework, weak linkage among different segments of operations in the sector, low market access, low credit and in effective linkage between industry and research institutes. This study attempts an empirical analysis of sectoral linkage in Nigeria with a view to ascertaining the leading and lagging sectors of the economy. The results will be useful for policy formulation, in fast tracking the various development projects in the country. In this paper, we used a more dynamic method that applies the unit root test and the granger causality test to determine the impact of the linkages between the manufacturing sector and other sectors of the Nigerian economy.

The paper is structured into five sections. Section I is the introduction while section II is the review of past literatures. Section III is the methodology and data analysis. Section IV is the empirical analysis, while section V is the conclusion and policy implications.

\section{Literature review}

There are important linkages and dynamic interactions between different sectors of the economy such that, "the relationship between agriculture and industry is one of interdependence and complementarities Hwa [6]. Relatively, Norman, Tim and Marina [7] suggest that it is important to understand these intersectoral linkages since government policies are often aimed at boosting the output of particular sectors. Examining the link between services and manufacturing from the dimension of liberalization in Philippine, Pasadilla and Liao [8] observed that globalization and pressure from increased competition have caused a stronger linkage in the service and manufacturing sectors in most economies. Their analysis shed light on the kind of linkage that exist between the services and manufacturing sectors, whether services contribute significantly as an input to manufacturing sector output. Also, they expressed the relative contribution of services to the growth in manufacturing output as liberalization evolved. Pilat and Wolfl [9] focused on the linkage between services and manufacturing in a number of OECD member countries. They found that the value added from the services sector to manufacturing production has increased over time and reached up to a quarter of total output in certain OECD nations by the mid-1990s. Also they discovered a growing share of labour that officially belonged to the 
manufacturing sector basically engaged in service-related activities. Memon, Waqar and Muhammed [10] examined the causal relationship between manufacturing exports and agricultural GDP and found out that a major share of exports has strong backward linkages with the agricultural sector both in terms of primary and value added commodities, including a bi-directional Grangercausality between total exports and agricultural GDP. Applying the same test of causality, Shombe [11] investigates the causal relationships within agriculture, manufacturing and exports; he found evidence of Granger causality that agricultural outputs induce growth in exports and manufacturing. However, he established a positive relationship between real GDP, real exports, real manufactured exports, and real primary exports. Similarly, Khan [12] observed that the construction industry generates substantial employment and provides a growth impetus to other sectors, including the manufacturing sector, through backward and forward linkages. Following the empirical studies of Kwan and Cotsomitis [13], Lee [14], Kwan and Kwok [15] Wong and Tang [16] They observed that in recognition of the strategic importance of these sectors, both the manufacturing and service sectors; will continue to be the 'twin engines' of growth, emphasizing that manufacturing and services mutually reinforce each other. They affirmed that diversifying the manufacturing sector to high value chain activities could generate derived demand for services ranging from logistics and ports to business and finance. In addition, they observed that, a strong complementary services sector could encourage more manufacturing activities capable of creating a mutually reinforcing growth cycle, even in the absence of causation. Therefore, they suggest an employment linkage running only from the manufacturing sector to the services sector and not in the reverse direction. This establishes the movement of the manufacturing sector upstream the value chain from downstream activities making an expansion of skilled workforce in this sector to potentially create employment in the services sector ranging from logistics and information technology to business and finance.

\subsection{Empirical literature}

Empirical studies abound in the literature explaining sectoral linkage. Norman et al [7] used the vector autoregressive (VAR) framework and offered an account of the patterns of sectoral interdependence in Malaysia's economy. This method facilitates the investigation of related concepts of exogeneity and temporal precedence or basically Granger-causality. They analyzed the data on Malaysian sectoral GDP and labour productivity using the logarithms of sectoral GDP in agricultural, manufacturing and services sectors. From their estimation, the results implied that in the long run only agriculture adjusts to sectoral disequilibrium within the economy and by virtue of the VAR(1) specification, the result indicates that agricultural output does not Granger-cause growth in the manufacturing or service sectors outputs. Interestingly, manufacturing and services sectors Granger-causes growth in the agricultural GDP. Moreover, they insisted that these results are informative regarding the relative importance of changes in manufacturing and services on the size of agricultural sector over the long term. 
Relatively, Michael, Ali and Azmat [17] detected a two-way relationship in their empirical investigation of the spill over effects of services and manufacturing sectors in the Association of South-East Asian Nations (ASEAN) countries. They hypothesized that the growth of the services sector is influenced by the growth of the manufacturing sector and that the growth of the manufacturing sector can be influenced by growth in the services sector. The empirical outcomes support both hypotheses revealing a strong, positive bidirectional influence in the growth of services and manufacturing sectors. Specifically, they noticed that the increase in the growth of the services sector has also triggered a growth in demand for a variety of manufactured goods. Wong et al [16] used a tri-variate vector autoregressive (VAR) framework by implementing the Granger-causality test in a VAR framework and tested the individual time series of the three variables. Their results indicate that inward Foreign Direct Investment (FDI) does not promote employment in the manufacturing (EM) and service (ES) sectors because the time horizon of a 3month lag is too short for inward FDI to have any impact on EM and ES. Also, they found a unidirectional causality, running from EM and ES to FDI inflows and evidences showing strong employment linkages predominantly from the manufacturing to services sector.

\section{Methodology}

The paper is a clear departure from the input-output framework Leontief [18] and the sectorial linkage study by Hirschman [19], but it followed the approach adopted by Wong et al [16]. In accordance with Sims [20] we estimate a multivariate autoregressive models and used an unrestricted vector autoregressive model (VAR) to evaluate the manufacturing sector linkage with other sectors of the Nigerian economy.

\subsection{Data analysis and model}

The data used for this study was obtained from the CBN [5]. The frequency of the data is quarterly and the sample ranges from 1980:1 to 2010: I. The variables used includes; Real Gross Domestic Product (RGDP), Manufacturing Output (MANU), Agricultural output (AGRI), Building and Construction Output (BUCN), Telecommunication and Post (TEPO), Financial Service Output (FINS), Crude Petroleum and Natural Gas (CRNG), Utility (UTIL), Wholesale and Retail Trade (WHRT), Hotel and Restaurant (HORT), Solid Minerals (SOLM), Real Estate (REST), and other Business Services (BUSS).

The method used in the analysis is VAR modeling technique which is expressed as;

$$
\begin{gathered}
y_{1 t}=\beta_{1}+\beta_{11} y_{1 t-1}+\beta_{12} y_{2 t-1}+\alpha_{11} y_{1 t-2}+\alpha_{12} y_{2 t-2}+\epsilon_{1 t} \\
y_{2 t}=\alpha_{1}+\beta_{21} y_{1 t-1}+\beta_{22} y_{2 t-1}+\alpha_{21} y_{1 t-2}+\alpha_{12} y_{2 t-2}+\epsilon_{2 t}
\end{gathered}
$$


The VAR equation can be written more compactly as;

$$
y_{t}=\alpha+\beta_{1} y_{t-1}+\beta_{2} y_{t-2}+u_{t}
$$

Where $\alpha$ is an $\mathrm{n} \times 1$ vector and the $\beta_{\mathrm{j}}$ 's are $\mathrm{n} \times \mathrm{n}$ metrics and $u_{t}$ is an $\mathrm{n} \times 1$ vector of serially uncorrelated random error which has a multivariate normal distribution $/ u_{t} \sim \operatorname{iidN}\left(0, \sigma^{2} I\right)$. Assuming $\mathrm{Y}_{t}$ is an $\mathrm{n} \times 1$ column vector composed of all the transformed variables listed for this study. A VAR relates current values of $\mathrm{Y}_{t}$ to past values of $\mathrm{Y}_{t}$ and an $\mathrm{n} \times 1$ vector of innovations $\mathrm{U}_{t}$. The Granger causality test used for this study is based on the assumption that future values cannot predict past or present values. The test consists of estimating the following equations for the manufacturing sector and the level of economic activities (RGDP) over the periods 1986 Q1 to 2010 Q1 using data obtained from the central bank of Nigeria Statistical Bulletin.

$$
\begin{aligned}
& \operatorname{LRGDP}_{t}=\alpha_{0}+\sum_{t=1}^{n} \alpha_{1} \text { LGDP }_{t-1}+\sum_{t=1}^{n} \alpha_{2} \text { LMANU }_{t-1}+U_{t} \\
& \text { LMANU }_{t}=\alpha_{0}+\sum_{t=1}^{n} \beta_{1} \text { LMANU }_{t-1}+\sum_{t=1}^{n} \beta_{2} \text { LRGDP }_{t-1}+V_{t}
\end{aligned}
$$

Where $U_{t}$ and $V_{t}$ are the uncorrelated error terms. Causality is determined by estimating equations five and six and testing the null hypothesis that $\sum_{i=1}^{n} \alpha_{2 i}=0$ and $\sum_{i=1}^{n} \beta_{2 i}=0$ against the alternative hypothesis $\sum_{i=1}^{n} \alpha_{2 i} \neq 0$ and $\sum_{i=1}^{n} \beta_{2 i} \neq 0$ for both equation respectively.

Similarly, to extend the linkage study to other sectors of the economy, we respecify the model as follows by incorporating other sector variables into the VAR model.

From equation four and five, if the coefficients of $\alpha_{2 i}$ are statistically significant but $\beta_{2 i}$ are not statistically significant, then there exist a unidirectional relationship between manufacturing output and RGDP with the causation moving from manufacturing output to RGDP. The reverse causation holds if the coefficient of $\alpha_{2 i}$ are statistically significant while $\beta_{2 i}$ are not. However, if the coefficients of $\alpha_{2 i}$ and $\beta_{2 i}$ are statistically significant, then there exist a bi-directional relationship. Conversely, we can use the Granger causality test to establish the relationships between the variables in the economy. The null hypothesis of no causality is rejected if the F statistics exceed the critical values at the 1 percent, 5 percent or the 10 percent levels of significance.

Given that most time series variables are non stationary, we will first establish the stationarity properties for each of the variables before estimating the VAR 
model. All the variables will be tested for the presence unit root using the Dickey Fuller (DF), the Augmented Dickey Fuller (ADF) and the PhillipsPerron (PP) tests.

\subsection{Empirical analyses}

The data used for this study was obtained from the CBN [5]. The frequency of the data is quarterly and the sample ranges from 1986:1 to 2010: I. The variables used in the study are in their natural log form.

\subsubsection{Unit root test}

The stationarity test using the DF, ADF and the PP, are summarized in Appendix 1 , Table 1 . The null hypotheses of non-stationarity are performed at the usual one percent, five percent and ten percent levels using the Mackinnon [21] critical value for rejection of hypothesis of a unit root. The critical values for the test are presented in Table 2. The result of the DF tests indicate that all the data series are non stationary at their individual levels with the exception of BUCN, TEPO, FINS, CRNG, UTIL, WHRT, HORT and REST that passed the test of significance at the one percent and five percent levels of significance. Based on the ADF test and the PP test, all the variables became stationary at their first difference, passing the test of significance at the one percent levels with the exception of manufacturing output that passed at the five percent levels of significance in the ADF test at first differencing. The implication of this result is that analyzing the data set at their levels would yield spurious and nonsense correlation Granger and Newbold [22].

\section{Appendix 1}

Table 1: Unit root tests: Nigeria sectoral output data, seasonally adjusted.

\begin{tabular}{|c|c|c|c|c|c|c|}
\hline \multirow{2}{*}{ Series } & \multicolumn{2}{|c|}{ DF Test at Levels } & \multicolumn{2}{c|}{$\begin{array}{c}\text { ADF Test in First } \\
\text { Difference }\end{array}$} & \multicolumn{2}{c|}{$\begin{array}{c}\text { PP Test in First } \\
\text { Difference }\end{array}$} \\
\cline { 2 - 7 } & With Trend & Lags & With Trend & Lags & With Trend & BW \\
\hline Lrgdp & -0.3845 & 5 & $-3.9723^{*}$ & 3 & $-12.1531^{*}$ & 14 \\
\hline Lagri & -1.2514 & 3 & $-3.9227^{*}$ & 3 & $-13.7785^{*}$ & 14 \\
\hline Lbucn & $-2.0924^{* *}$ & 7 & $-4.6107^{*}$ & 3 & $-15.0732^{*}$ & 13 \\
\hline Lbuss & -1.6101 & 10 & $-9.7578^{*}$ & 4 & $-17.8754^{*}$ & 13 \\
\hline Lcrng & $-1.7696^{* * *}$ & 3 & $-4.6946^{*}$ & 3 & $-27.7415^{*}$ & 14 \\
\hline Lfins & $-2.5054^{* *}$ & 3 & $-3.3075^{*}$ & 3 & $-13.2291^{*}$ & 13 \\
\hline Lhort & $-2.4968^{* *}$ & 3 & $-3.8704^{*}$ & 7 & $-23.8516^{*}$ & 21 \\
\hline Lmenu & -1.0105 & 10 & $-2.4047^{* *}$ & 11 & $-50.0076^{*}$ & 13 \\
\hline Lrest & $-1.7407^{* * *}$ & 5 & $-3.4282^{*}$ & 5 & $-15.1752^{*}$ & 13 \\
\hline Lsolm & -0.2971 & 3 & $-4.3414^{*}$ & 3 & $-13.4322^{*}$ & 13 \\
\hline Ltepo & $-9.0388^{*}$ & 1 & $-9.1644^{*}$ & 1 & $-10.3163^{*}$ & 13 \\
\hline Lutil & $-8.2912^{*}$ & 1 & $-9.0458^{*}$ & 1 & $-9.5011^{*}$ & 15 \\
\hline Lwhrt & $-15.2440^{*}$ & 0 & $-11.6978^{*}$ & 2 & $-49.4911^{*}$ & 23 \\
\hline
\end{tabular}

(1986:1-2010:1) The values $* * *$ and $* * *$ indicates statistical significance at $1 \%$, $5 \%$ and 10\% respectively Source: Author's estimation using e-view 7 
Table 2: $\quad$ Mac-Kinnon critical values for rejection of hypothesis of unit root.

\begin{tabular}{|c|c|c|c|c|}
\hline \multirow{2}{*}{$\begin{array}{c}\text { Critical } \\
\text { Value }\end{array}$} & \multicolumn{2}{|c|}{ DF Test at Levels } & \multicolumn{2}{c|}{ ADF Test in First Difference } \\
\cline { 2 - 5 } & No Trend & With Trend & No Trend & With Trend \\
\hline $1 \%$ & -2.5909 & -3.6180 & -3.5031 & -4.0604 \\
\hline $5 \%$ & -1.9445 & -3.0620 & -2.8932 & -3.4594 \\
\hline $10 \%$ & -1.6144 & -2.7700 & -2.5837 & -3.1558 \\
\hline
\end{tabular}

Source: Author's estimation using e-view 7

Table 3: Inter- sectoral causality tests of the sectors in the Nigerian economy.

\begin{tabular}{|c|c|c|c|c|c|}
\hline \multicolumn{3}{|c|}{ Table 3a (Manufacturing Sector Linkage) } & \multicolumn{3}{|c|}{ Table 3b (Agricultural Sector Linkage) } \\
\hline $\begin{array}{c}\text { Direction } \\
\text { of } \\
\text { Causality }\end{array}$ & $\begin{array}{c}\text { Lag } \\
\text { Length }\end{array}$ & F-Statistics & $\begin{array}{l}\text { Direction of } \\
\text { Causality }\end{array}$ & $\begin{array}{c}\text { Lag } \\
\text { Length }\end{array}$ & F-Statistics \\
\hline $\begin{array}{c}\Delta \text { lmanu } \Rightarrow \\
\Delta \text { lagri }\end{array}$ & 4 & 0.3526 & $\Delta$ lagri $\Rightarrow \Delta \operatorname{lmanu}$ & 4 & 0.1911 \\
\hline $\begin{array}{c}\Delta \operatorname{lmanu} \Rightarrow \\
\Delta \mathrm{Icrgn}\end{array}$ & 4 & $2.3550 * *$ & $\Delta$ Lutil $\Rightarrow \Delta \operatorname{lmanu}$ & 3 & 0.8322 \\
\hline $\begin{array}{c}\Delta \text { Lmanu } \Rightarrow \\
\Delta \text { lbuss }\end{array}$ & 7 & $0.5 / 544$ & $\Delta$ Lsolm $\Rightarrow \Delta \operatorname{lmanu}$ & 7 & 1.4201 \\
\hline $\begin{array}{c}\Delta \text { Lmanu } \Rightarrow \\
\Delta \text { lhort }\end{array}$ & 4 & $5.8710^{*}$ & $\Delta$ Lbucn $\Rightarrow \Delta \operatorname{lmanu}$ & 4 & $2.7049 * *$ \\
\hline $\begin{array}{c}\Delta \text { Lmanu } \Rightarrow \\
\Delta \text { dlrest }\end{array}$ & 8 & $2.5064 * *$ & $\Delta$ Lrest $\Rightarrow \Delta \operatorname{lmanu}$ & 8 & 1.4055 \\
\hline $\begin{array}{c}\Delta \text { Lmanu } \Rightarrow \\
\Delta \mathrm{lsolm}\end{array}$ & 7 & 1.1740 & $\Delta$ Lwhrt $\Rightarrow \Delta \operatorname{lmanu}$ & 3 & 0.2996 \\
\hline $\begin{array}{c}\Delta \text { Lmanu } \Rightarrow \\
\Delta \text { ltepo }\end{array}$ & 3 & $5.7848^{*}$ & $\Delta$ Ltepo $\Rightarrow \Delta \operatorname{lmanu}$ & 3 & 0.3499 \\
\hline $\begin{array}{c}\Delta \text { Lmanu } \Rightarrow \\
\Delta \text { lutil }\end{array}$ & 3 & 0.0197 & $\Delta$ Lcrgn $\Rightarrow \Delta \operatorname{lmanu}$ & 4 & 1.4008 \\
\hline $\begin{array}{c}\Delta \text { Lmanu } \Rightarrow \\
\Delta \text { lwhrt }\end{array}$ & 3 & $3.8341 *$ & $\Delta$ Lbuss $\Rightarrow \Delta$ lmanu & 7 & 1.2158 \\
\hline $\begin{array}{c}\Delta \text { Lmanu } \Rightarrow \\
\Delta \text { Bucn }\end{array}$ & 4 & 1.5373 & $\Delta$ Lhort $\Rightarrow \Delta \operatorname{lmanu}$ & 4 & $2.8401^{*}$ \\
\hline $\begin{array}{c}\Delta \text { Lmanu } \Rightarrow \\
\Delta \text { lfins }\end{array}$ & 5 & 0.32289 & $\Delta$ Lfins $\Rightarrow \Delta \operatorname{lmanu}$ & 4 & 1.4276 \\
\hline \multirow{2}{*}{\multicolumn{3}{|c|}{$\begin{array}{l}\text { The values } *, * * \text { and } * * * \text { indicates statistical } \\
\text { significance at } 1 \%, 5 \% \text { and } 10 \% \text { respectively } \\
\text { Source: Author's estimation using e-view } 7\end{array}$}} & $\Delta \operatorname{lrgdp} \Rightarrow \Delta \operatorname{lmanu}$ & 4 & 0.9320 \\
\hline & & & $\Delta \operatorname{lmanu} \Rightarrow \Delta \operatorname{lrgdp}$ & 4 & 0.9214 \\
\hline
\end{tabular}

\subsection{Sectoral interdependence test}

The Granger causality test is used to determine whether a change in the manufacturing sector output precedes the other outputs of other sectors within the Nigerian economy. The approach adopted for this study is similar to the approach adopted by Raze [23] study on the role of construction sector in economic growth for the Pakistan economy and the approach adopted by Chen 
[24] on the linkage between construction and other economic sectors in Singapore. The Granger Causality test, in Appendix 1; Table 2, is used to test whether manufacturing sector stimulates the other sectors of the Nigerian economy and real economic aggregate as measured by RGDP or whether changes in the other sectors of the economy stimulates the manufacturing sector.

\subsubsection{The manufacturing sector and the other sectors of the economy}

Table 3a demonstrates the sectoral linkage between the MANU and the other sectors of the Nigerian economy. The result shows that the MANU granger causes TEPO, CRNG, WHRT, HORT and REST. The relationship between the MANU output and the output of these sectors is a unidirectional relationship moving from the MANU to the various sectors. It takes approximately four quarters (one year) for CRNG and HORT to respond to changes in the MANU output. It takes eight quarters (two years) for REST output to respond to changes in the MANU sector while it takes three quarters (nine months) for TEPO output and WHRT output to respond to changes in MANU output. Therefore, it was noticed that MANU sector output responds to changes in two major sectors BUCN and HORT with the later exhibiting a bidirectional relationship with the MANU. The result showing the relationship between the MANU and RGDP is reported in Table 3b, the result shows that MANU output does not granger cause the RGDP and RGDP does not granger cause the manufacturing sector.

\subsubsection{Other sectors of the economy and the manufacturing sector}

Building and construction: The estimates obtained from the granger causality test in Table $3 b$, disclose that the BUCN and the MANU sector outputs are unidirectional and statistically significant at five percent. This sector granger causes RGDP.

Hotel and restaurant sector: Estimates of the granger causality test expressed, reveals that the HORT sector output granger causes MANU sector. The causal link from the HORT sector to other sectors in the economy depicts a unidirectional relationship which basically moves from the services rendered by the HORT sector to the other sectors in the economy. On the average, it takes close to four quarters (one year) for MANU to respond to changes in the HORT sector. This sector granger causes RGDP.

Wholesale and retail trade sector: Changes in WHRT sector appear to have no immediate effects on all the sectors of the economy as shown in Table $3 \mathrm{~b}$. However, the WHRT sector output is preceded by changes in MANU sector. Relatively, the sector does not impact on the level of economic activity as measured by RGDP and changes in RGDP do not explain changes in the WHRT sector.

Agricultural sector: Table $3 \mathrm{~b}$ presents the report of the linkages between AGRI and other sectors; the result shows that AGRI did not precede MANU but it has a bidirectional relationship existing between agricultural output and SOLM sector. Also, it was noticed that AGRI output does not granger-cause RGDP and RGDP does not granger cause the agricultural sector. 
Financial sector: From the result it was detected that FINS does not grangercause the MANU output but it granger causes CRNG, BUCN, HORT, WHRT and CRNG sector.

Utility sector: The UTIL sector which is made up of electricity and water only granger caused the level of output in the AGRI, CRNG and the FINS sectors. The UTIL sector does not granger cause MANU but it exhibits a bidirectional relationship with RGDP. This is an indication that a stable and reliable UTIL (i.e. power sector) is a sine qua non for sustainable growth and development in the Nigeria economy.

Real estate sector: The estimates of the causality test expressed in Table $3 b$, reveals that REST does not granger cause MANU sector output but its granger causes CRNG, BUSS, BUCN, HORT, SOLM, TEPO and WHRT. It takes approximately six quarters for these sectors to respond to changes in the REST sector. The link between the REST and RGDP, takes 4 quarters (one year) to respond to changes in the level of economic activities and the relationship is unidirectional moving from RGDP to the REST.

Telecommunications and postal service sector: The result indicates that the TEPO sector output indicate that this sectors output does not granger cause MANU. The result reveals that this sector has very small and in most cases insignificant influence on the other sectors of the economy.

Other business service sector: The estimates obtained revealed that the BUSS did not granger cause MANU sector output but its output and the output of the CRNG, HORT, REST, SOLM, TEPO, WHRT and FINS sector are unidirectional which means, a one way casual relationships exist among them. In general the results expressed, states the fact that it takes over a year for the other sector in the economy to respond to changes in the BUSS and that the response of the MANU, AGRI, UTIL, and the BUCN sectors were statistically significant at both the one and five percent levels. This sectors output does not granger cause RGDP.

Crude petroleum sector: The results disclose that the CRNG sector output does not granger cause MANU. Although it will take approximately four quarters for the MANU sector to respond to relatively similar impacts of a magnitude of change in the CRNG sector output at less significant impacts. Therefore, it is important to note that the nature of causality between these variables analyzed is unidirectional and CRNG output does not granger cause RGDP.

Solid mineral sector: This result exposes the fact that there are no linkages between the output of the SOLM sector and MANU. Also, the MANU sector has low statistical significance in response of changes in the outputs of the SOLM sector. In addition, it takes the MANU sector about seven quarters, to respond to similar impacts from the SOLM sector outputs but these variables where found not to be statistically significant. 


\section{Discussions of findings}

The findings of this study shows that manufacturing sector (MANU) granger causes BUCN, HORT and WHRT with the direction of causality moving from the MANU sector output to these sectors. Two major sectors, BUCN and HORT however, exhibited bidirectional relationships with the MANU sector. Further, the result indicates that there was no defined relationship between the MANU sector output and RGDP.

The AGRI, FINS, UTIL, REST, SOLM, TEPO, CRNG and BUSS sectors output, does not granger cause MANU output. Also, it was disclosed that the impact of changes from the outputs of BUCN, HORT, UTIL, TEPO and BUSS sectors granger cause RGDP while others did not. Interesting is the fact that shocks from changes in RGDP has positive impacts on the outputs of CRNG, BUCN, HORT, UTIL and REST.

The output of building and construction (BUCN), hotel and restaurants (HORT) and utility sector (UTIL) exhibited a bidirectional relationship with RGDP indicating that a stable and consistent increase in these sectors output is necessary and strongly associated to economic growth. Changes in the WHRT output precede changes in other sectors of the economy such as MANU, FIN and CRNG etc. The linkages between REST and RGDP take approximately four quarters to adjust to change in RGDP, from a unidirectional perspective moving from RGDP to REST. The HORT output was noticed to granger-cause other key sectors besides MANU sector. The effect of the shocks were unidirectional, they were noticed to move from services rendered by the HORT sector to other sectors of the economy. For TEPO output, its relationship with other sectors of the economy is minimal and its expected shocks effects are insignificant. While the BUSS exhibits a unidirectional relationship with most sectors of the economy. The financial sector output revealed a bidirectional relationship with the BUSS and BUCN. Also, SOLM contributed significantly to most of the key sectors of the economy but the impact of shocks from the output of this sector did not influence changes in MANU and RGDP. Worth knowing is the fact that the impact from the shocks of BUCN output relates cordially with the outputs of most of the sectors of the economy, but the effects of these shocks were minimal for the UTIL sector output.

\section{Conclusion and policy implications}

The paper carried out empirical test on the linkage between the manufacturing (MANU) sector and other sectors of the Nigerian economy using quarterly data from 1986 to 2010 . The main idea behind this study is to observe the behaviour of the interrelations of all the sub-sectors of the Nigerian economy and their relationship with the level of economic activities as measured by real gross domestic product (RGDP). Interestingly, the result showed that there is no causal relationship between the real output and manufacturing sector output (MANU) in Nigeria. RGDP does not precede the manufacturing sector and the MANU sector does not precede RGDP. Only two major sectors Building and 
Construction (BUCN) and Hotel and Restaurant (HORT) seems to be driving the manufacturing sector with the later exhibiting a bi-directional relationship with the MANU sector. A notable feature of the Nigerian economy is policy inconsistency. The findings of this study show that it takes approximately four to eight quarters for one sector to respond to changes in the other sectors on the economy hence the need for continuity, consistency and stability in Government policies. Also, the weak linkage between the various sectors can be linked directly to the problems of epileptic power supply, poor infrastructure, poor road net work and logistics, weak linkage between the manufacturing sector and the various research institutions which if properly addressed will put Nigeria on the path of sustainable development and economic growth.

\section{References}

[1] Cornwall, J., Modern Capitalism its Growth and Transformation, New York: St. Martin's Press, 1977.

[2] Fagerberg, J. and Verspagen, B. 1999. "Modern Capitalism in the 1970s and 1980s", Working Paper Archive, 1999002, Centre for Technology, Innovation and Culture, University of Oslo.

[3] Timmer, M. P. and Vries, G. J. de, "A Cross-country Database for Sectorial Employment and productivity in Asia and Latin America, 1950-2005," GGDC Research Memorandum GD-98, Groningen Growth and Development Centre, University of Groningen, 2007.

[4] Szirmai, A., "Industrialization as an engine of growth in developing countries", UNU-MERIT Working Paper Series 010, United Nations University, Maastricht Economic and Social Research and training Centre on Innovation and Technology, 2009.

[5] Central Bank of Nigeria, Statistical Bulletin, 50 Years Special Anniversary Edition, Central Bank of Nigeria, December, 2008.

[6] Hwa, E. C., The Contribution Of Agriculture To Economic Growth: Some Empirical Evidence, in J. Williamson and V.R. Panchamurtchi (eds.), The Balance between Industry and Agriculture in Economic Development, Vol. 2, Sector Proportions. New York: The World Bank, 1989.

[7] Norman, G. Tim, L. and Marina, M., Dynamic Sectorial Linkages and Structural Change in a Developing Economy. Credit Research Paper No. 98/3 p. 6, 2007.

[8] Pasadilla, G.O. and Liao, C.M.M., "Has liberalization strengthened the link between services and manufacturing?" Discussion Paper Series DP 2007-13, Philippine Institute for Development Studies, p.2, 2007.

[9] Pilat, D. and Wolfl, A., Measuring the Interaction between Manufacturing and Services, Working Paper, Organization for Economic Cooperation and Development Statistical Analysis of Science, Technology and Industry, 2005.

[10] Memon, H.M., Waqar S.B., and Muhammed, A., "Causal Relationship between Exports and Agricultural GDP in Pakistan," Munich Personal RePEd Archive Paper No. 11845 p. 2, 2008. 
[11] Shombe, N.H., "Causality Relationships between Total Exports with Agricultural and Manufacturing GDP in Tanzania", Institute of Developing Economies, Discussion Paper No. 136, 2005.

[12] Khan, K., Employment of foreign workers male and female labour market participation, Office for National Statistics, UK, 2008.

[13] Kwan, A. C. C. and Cotsomitis, J. A. K., "Economic Growth and Exogeneity: Taiwan 1953-88", The American Economist, 28(4):467-471(5), 1991.

[14] Lee, J.W., "International Trade, Distortion and Long-run Economic Growth," International Monetary Fund Paper, 40(2):299-328, 1993.

[15] Kwen, A. and Kwok, B., "Exogeneity and the Export-led Growth Hypothesis: The case of China", Southern Economic Journal, vol. 61, pp. 1158-1166, 1995.

[16] Wong, K. N. and Tang, T. C., "Foreign Direct Investment and Employment in Manufacturing and Services sectors: Fresh Empirical Evidence from Singapore", Monash Economics Working Papers 15/08, Monash University, Australia. p.11, 2008.

[17] Michael, D.C., Ali, A. and Azmat, G., "An Empirical Investigation of the Spillover Effects of Services and Manufacturing Sectors in ASEAN Countries", Asian-Pacific Development Journal, 10(2):10, 2003.

[18] Leontief, W., The Structural of America Economy 1919-1939, Second Edition Input Output Economic. Oxford University Press, 1951.

[19] Hirschman, A. O., The Strategy of Economic Development, Yale University Press, New Haven, CT, 1958.

[20] Sims, C. A., "Macroeconomics and Reality" Econometrica, 48 (10), pp.1-48, 1980.

[21] Mackinnon, J. 1991. Critical value for Cointegration Test, In Engle, R.F and Granger, C.W.J, eds., Long-Run Economic Relationships, Oxford University press.

[22] Granger, C.W.J and Newbold. P., "Spurious Regression in Econometrics", Journal of Econometrics, 2, 111-20, 1974.

[23] Raza. A.K., Role of construction sector in Economic Growth: Empirical Evidence from Pakistan Economy. First international conference on construction in developing countries (ICCIDC-I) paper p. 2, 2008.

[24] Chan, S. L., "Empirical test of discern linkages between construction and other sectors of the economy", Construction Management and Economic, vol. 19, Issue 4, pp. 355-363, 2001. 